\title{
Correlation of Power Prediction Considering the Nominal Operating Cell Temperature under Partial Shading Effect
}

\author{
Pedram Asef, Student Member, IEEE, Payam Niknejad, Student Member, IEEE, M. R. Barzegaran, Member, \\ IEEE, Ramon Bargallo, Andrew Lapthorn, Member, IEEE,
}

\begin{abstract}
The steadily rising efficiency together with the precision of prediction in solar photovoltaic (PV) energy requires a deterministic reliability in the performance estimation. This research determines an underlying output prediction fault of a solar PV module that originates from ignoring nominal operating cell temperature (NOCT) consideration. The impact of NOCT consideration is investigated to minimize the maximum power prognosis fault for the PV modules, where the significant parameters of the maximum power point tracking (MPPT) controller used such as current, output power are measured under partial shading condition. A set of non-parametric correlations are calculated using Spearman's $\rho$ and Kendall $\tau$ rank statistical methods in order to provide a fast true estimation, as well as avoid experimental measurement difficulties and cost for an advanced output power prediction. Finally, the findings have been numerically and experimentally verified to enhance the forecasting accuracy which may significantly affects the engineer's cost benefit estimations prior to any operational enterprise.
\end{abstract}

Index Terms-Fault Prognosis, Solar Photovoltaic Module, Partial Shading Effect, Correlation, Cell Temperature, Power Forecasting.

\section{INTRODUCTION}

$\mathrm{N}$ OWADAYS the pace of research is very coherent among researchers for predicting the solar photovoltaic (PV) module's output power under various conditions [1]. Solar irradiance is the most significant factor for characterizing the magnitude of power generated in the cell and cell temperatures are the second most significant factor [2-3]. These factors are dependent on a number of data such as cell temperature, partial shading effect, wind speed etc.

Most of the applications corresponding to the field of PV need to evaluate the temperature of the PV cells as well as the solar radiation incident on them with adequate precision and reliability [4]. This is because the $I-V$ curve of the photovoltaic module depends on the temperature and incident solar irradiation [5-7].

There is valuable research in the literature that has been reported in recent years to enhance the solar PV performance prediction [8-17]. Among them, some methods

Pedram Asef is a Ph.D. degree candidate with the Department of Electrica Engineering, Technical University of Catalonia-BarcelonaTech, EEBE, 08019 Barcelona, Spain. (corresponding author email: pedram.asef@upc.edu).

Payam Nicknejad is a doctoral degree candidate from Lamar University (A Texas State University), TX, USA (email: pniknejad@lamar.edu).

Dr. Barzegaran is Assistant Professor and Director of Renewable energy Microgrid Laboratory at Lamar University (A Texas State University), TX USA (email: barzegaran@lamar.edu). include the basis of module operating temperature measurement techniques [8-9], the uncertainty performance loss-rate estimation measurement via indoor [10] and outdoor [11] techniques, and partial shading effect assessment approaches are also widely discussed [18-19].

G. Farivar and B. Asaei [20] presented an effective new method for estimating the operating temperature of a PV module with the simple diode model. The researchers have proposed the methodology, which is based on an analytical formula, in order to derive the temperature from the maximum power point, voltage and current. The work has been experimentally verified. In addition, other research by G. Mangeni, et al. [21], discussed a photovoltaic module's cell temperature measurement and an 81 point heat distribution mapping technique using only 9 temperature sensors. They used these 9 negative temperature coefficient thermistor based temperature sensors (NTC thermistor) attached at the back of photovoltaic panel equally spaced in a 3 by 3 manner, a microcontroller, a data acquisition and visualization software with interpolation technique developed in MATLAB.

Malte Ruben Vogt, et al. [22] studied the reduced operating temperature of modules made from passivated emitter rear cells (PERCs) compared with modules made from cells featuring an "unpassivated fullarea screen-printed aluminum rear side metallization aluminum back surface field (Al-BSF)". Additionally, they increased the yield of modules using PERC instead of Al-BSF solar cells. The research offers a valuable experimental investigation.

In P. Ingenhoven, et al. [23] paper, the researchers have compared statistical and deterministic smoothing methods to reduce the uncertainty of performance loss rate (PLR) predictions.

Based on the addressed references, the main reasons for solar PV material degradation are continuous cycles of temperature, humidity, irradiation, mechanical stress, spotted soiling that can induce corrosion of the metallic connections, hot spots, bubbles, and other failures [23-25]. In addition to material degradation, there are other considerable outdoor

Professor Ramon Bargallo Perpina is with the Department of Electrical Engineering, Technical University of Catalonia-BarcelonaTech, EEBE, 08019 Barcelona, Spain (email: ramon.bargallo@upc.edu).

Dr. Andrew Lapthorn is a Senior Lecturer at the Department of Electrica and Computer Engineering, University Of Canterbury, Christchurch, New Zealand (email: andrew.lapthorn@canterbury.ac.nz). 


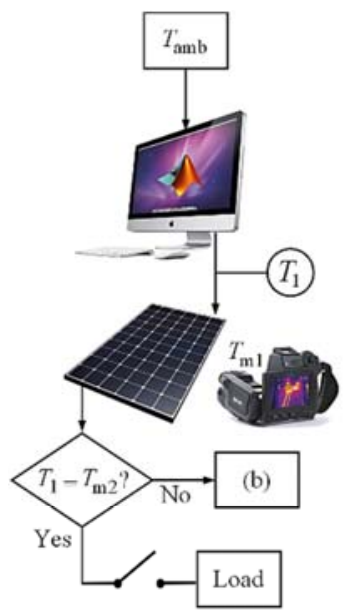

(a)

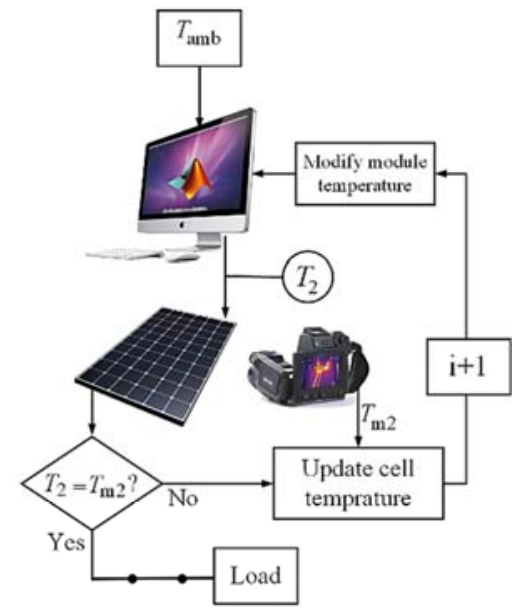

(b)

\begin{tabular}{|l|l|l|l|l|l|l|l|l|}
\hline$T_{11}$ & $T_{12}$ & $T_{13}$ & $T_{14}$ & $T_{15}$ & $T_{16}$ & $T_{17}$ & $T_{18}$ & $T_{19}$ \\
\hline$T_{21}$ & $T_{22}$ & $T_{23}$ & $T_{24}$ & $T_{25}$ & $T_{26}$ & $T_{27}$ & $T_{28}$ & $T_{29}$ \\
\hline$T_{31}$ & $T_{32}$ & $T_{33}$ & $T_{34}$ & $T_{35}$ & $T_{36}$ & $T_{37}$ & $T_{38}$ & $T_{39}$ \\
\hline$T_{41}$ & $T_{42}$ & $T_{43}$ & $T_{44}$ & $T_{45}$ & $T_{46}$ & $T_{47}$ & $T_{48}$ & $T_{49}$ \\
\hline$T_{51}$ & $T_{52}$ & $T_{53}$ & $T_{54}$ & $T_{55}$ & $T_{56}$ & $T_{57}$ & $T_{58}$ & $T_{59}$ \\
\hline
\end{tabular}

(c)

Fig. 1. Solar PV cells temperature measurement using (a) conventional, and (b) proposed strategies, for (c) the demonstrated module's cells matrix

operating conditions, such as partial shading analysis, which must be considered when a true output estimation is required. The following listed studies have allowed many researchers to evaluate their own Solar PV system under partial shading conditions [18-19].

The scope of this article is to introduce a new fast technique to estimate the performance metrics (output) of a solar PV module under a partial shading condition. In addition to this outdoor operating condition, the nominal operating cell temperature (NOCT) must be accounted for to avoid an incorrect prognosis during cell temperature measurement. In particular, this fact motivated us to experimentally test the cell temperature distribution during open/close circuits, as the PV module temperature settings have significant impact on the output prediction. This research offers correlations to reduce the difference between predicted values and experiments.

To find an accurate estimate of the output, it is necessary to follow the simple procedure shown in Fig. 1, where the flowchart (Fig. 1(a)) illustrates the conventional way to predict the module temperature, which is based on either the ambient temperature of the PV module or the open-circuit module temperature distribution. The captured PV characteristics under a close-circuit condition are derived in a different manner, in which the measurement restrictions is depicted in Fig. 1(b), for a high efficiency crystalline PV module with maximum output of $150 \mathrm{~W}, 7.6 \mathrm{~A}$. The cells temperature is studied cell by cell based on the presented cells coding in Fig. 1(c).

The studied output prediction and measurement are grouped in two distinct techniques, listed in the following. This paper is structured as follows. In Section II, the theoretical findings are discussed. In Section III, numerical-based results and comparisons between the two techniques are presented. In Section IV, the experimental setup and verifications are presented. The main contribution of the research is concluded in Section V.

\section{Theory of The Proposed Measurement TechniQue \\ A. Methodology}

Based on the proposed schematic illustrated in Fig. 1(b), the procedure to manage the cell temperature relies on a NOCT consideration. In addition to the load's impact, the effect of partial shading at different levels has been considered. In this section, we describe the method used to compute the cell temperature, namely:

1) Define the PV module in Matlab Simulink based on the ambient temperature using an average value of each month.

2) After storing the first estimations of the module's temperature $\left(T_{1}\right)$ and output. Then the experimental cell temperature (online) can be measured under load (closed-circuit) conditions.

3) The measured cells temperature $\left(T_{2}\right)$ can be seen to be considerably higher than $T_{1}$, therefore the output prediction has been affected due to the error of the PV module temperature as an input).

4) To avoid this defect, the input PV module temperature is updated monthly in Simulink. This back and forth measurement process comes with a cost, which has solved by step 5 .

5) All the data from both models ( $a$ and b) are stored within different shading-levels. Afterwards, pairwise and Spearman's $\rho$ statistical methods are applied to find out the best possible correlations with minimum error.

6) The proposed correlations as a function of NOCT and partial shading effects have resulted in a faster and more accurate estimation of the output.

\section{B. Mathematical Definitions}

The total solar irradiance that strikes the surface of the PV module $\left(\phi_{\text {total }}\right)$ can be defined by the harvested power $\left(P_{\mathrm{E}}\right)$ and wasted energy $\left(P_{\mathrm{L}}\right)$, where $P_{\mathrm{L}}$ is due to the light reflected or emitted through the module $\left(\phi_{\mathrm{o}}\right)$, and the power converted into heat $\left(\phi_{\mathrm{h}}\right)$. Thus, the effective power is calculated by:

$$
P_{E}=\phi_{\text {total }}-P_{L}=\phi_{\text {total }}-\phi_{o}-\phi_{h}
$$

For the simulation studies, the parameter $\phi_{\text {total }}$ is set by 800 W. $\mathrm{m}^{-2}$ in ambient temperature $T_{\mathrm{amb}}=20^{\circ} \mathrm{C}$, wind speed $\mathrm{v}=1$ $\mathrm{m} . \mathrm{s}^{-1}$, in addition, an optical density of luminescent down shifting (LDS) layers at dye peak absorption equals 2 . There is valuable research done regarding to the impact of LDS over NOCT in [3].

The cell temperature measurements, either IR-Infraredbased $\left(T_{\mathrm{m} 1}\right.$ and $\left.T_{\mathrm{m} 2}\right)$ or linear interpolation technique $\left(T_{1}\right.$ and $T_{2}$ ), have considered the module's cell coding or matrix (see Fig. 1(c)) [21]. In particular, to compare the outcome of both measurement techniques, the average string-based module 
temperature was calculated from:

$$
T_{1}=T_{2}=\sum_{i=1}^{9} T_{1 i}+T_{2 i}+T_{3 i} \cdots T_{5 i}
$$

Boundary conditions at the front surface of the glass and the back surface of the plastic are convection and radiation heat transfers which entirely discussed in [4]. Thus, the boundary conditions for the average PV module temperature $\left(T_{1}\right.$ or $\left.T_{2}\right)$ can be defined, for instance, when model (a) operates (see Fig. 1(a)) as:

$$
\begin{aligned}
& k_{1} \frac{\partial T_{1}}{\partial x}=h_{F S}\left(T_{1}-T_{a m b}\right)+q_{1} \\
& k_{2} \frac{\partial T_{1}}{\partial x}=h_{B S}\left(T_{a m b}-T_{1}\right)-q_{2}
\end{aligned}
$$

The relative efficiency deviation $\left(\Delta \eta_{\text {rel }}\right)$ as function of solar irradiance $(G)$ and cell temperature $\left(\mathrm{T}_{2}\right)$ can be defined as:

$$
\Delta \eta_{\text {rel }}\left(G, T_{2}\right)=\frac{P_{2, \text { max }}(G, T)}{P_{2, \max }} \times \frac{G_{S T C}}{G}-1
$$

Based on the self-reference method [26-28], using the shortcircuit current $\left(I_{\mathrm{sc}}\right)$ as a function of $G$ can be written as:

$$
\frac{G_{S T C}}{G}=\frac{I_{s c}\left(G_{S T C}, T_{2}\right)}{I_{s c}\left(G, T_{2}\right)}
$$

The module's temperature dependency during the partial shading phenomenon can be modeled through heat equations over each individual layer of crystalline silicon (C-Si) in the solar modules. In this study, it is assumed that the temperature diffusion is uniform at the horizontal plane. The heat equations are given for each layer by Eq. (1-3), in which the suffix $i$ varies between $20-100 \%$ depending to the shading rate.

$$
\begin{aligned}
& \frac{\partial T_{1}}{\partial t}=\alpha_{1} \frac{\partial^{2} T_{1}}{\partial x^{2}}+G_{i} \frac{\alpha_{1}}{\kappa_{1}} \frac{a_{1}}{X_{1}} \quad \text { (Glass) } \\
& \frac{\partial T_{2}}{\partial t}=\alpha_{2} \frac{\partial^{2} T_{2}}{\partial x^{2}}+G_{i} \frac{\alpha_{2}}{\kappa_{2}} \frac{a_{2}-P_{C-S i}}{X_{2}-X_{1}} \quad \text { (Silicon) } \\
& \frac{\partial T_{3}}{\partial t}=\alpha_{3} \frac{\partial^{2} T_{3}}{\partial x^{2}}+G_{i} \frac{\alpha_{3}}{\kappa_{3}} \frac{a_{3}}{X_{3}-X_{2}} \quad \text { (Plastic) }
\end{aligned}
$$

where $T_{1}, T_{2}$, and $T_{3}$ are the uniformed temperature of the glass, silicon, and plastic parts, respectively. $\alpha_{1}, \alpha_{2}$, and $\alpha_{3}$ are the thermal diffusion constants which are $3.77 \times 10^{-7}, 7.65 \times 10^{-6}$, and $1.86 \times 10^{-7}\left(\mathrm{~m}^{2} . \mathrm{s}^{-1}\right)$, respectively. $P$ is the generated power in the silicon layer given as:

$$
P_{C-S i}=I_{s} \frac{V_{s}+0.75}{m \times 60 S}
$$

where $I_{\mathrm{s}}$ and $V_{\mathrm{s}}$ are the current and voltage of the string (including the cell). $m$ is the number of solar PV modules in series, as we tested the measurement for only a single module, thus, $m=1.60 S$ represents the number of cells, which is 60 in this study. Finally, $S$ is the total active area of the cell in $\mathrm{m}^{2}$.

Fig. 2-a presents a cross-sectional model of the C-Si solar PV cells, in which the PV module has been implemented at Barcelona in Spain. The thickness of glass, silicon, and plastic back sheet have been measured and are $X_{1}=3.5, X_{2}-X_{1}=0.28$, $X_{3}-X_{2}=0.6(\mathrm{~mm})$, respectively. There are also two ethylene vinyl acetate copolymer (EVA) layers encapsulating the C-Si layer, which are considered in the model. The EVA layers over the $\mathrm{C}$-Si layer are transparent and considerably thinner than the glass layer [29].

\section{A. C-Si Photovoltaics Module Characteristics}

The 60 cells, C-Si, PV module with a nominal output power of $150 \mathrm{~W}, 7.6 \mathrm{~A}$, under different partial shading rates $(S=0$ $80 \%$ ), and open circuit test conditions has the I-V and P-V curves presented in Fig. 3(a) and (b).

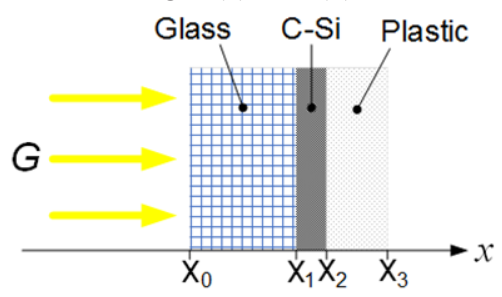

(a)

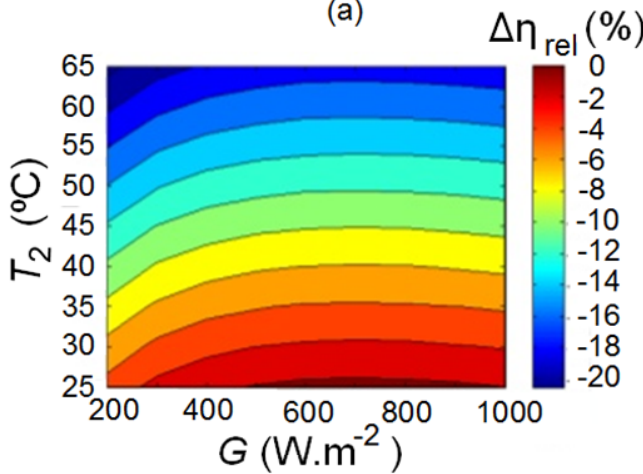

(b)

Fig. 2. Cross-sectional model of used C-Si solar module, where (a) indicates the solar irradiance versus module partitions, and (b) irradiance and temperature dependence of C-Si PV module

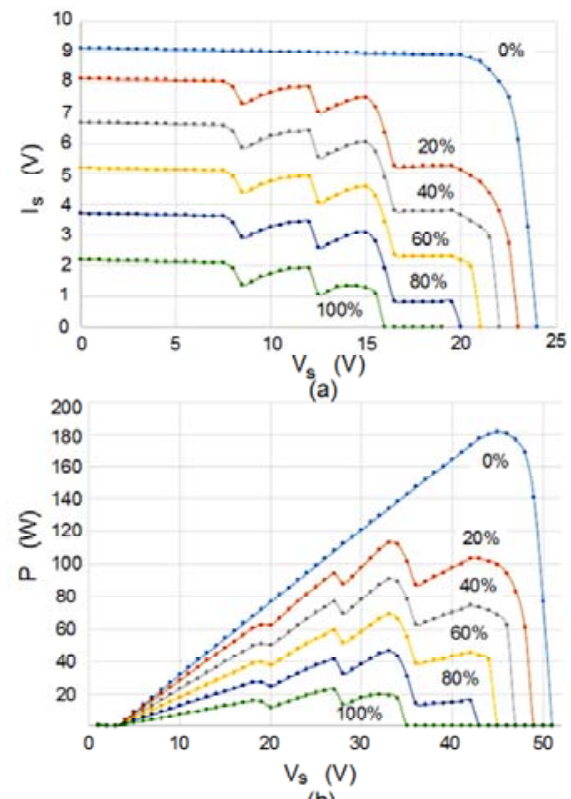

(b)

Fig. 3. Solar C-Si 60 cells PV module characteristics based on partial shading effect, (a) I-V, (b) P-V curves. 


\section{RESULTS AND DISCUSSION}

In this section, the behavior of the $\mathrm{C}$-Si module under all defined considerations and assumptions have been collated and analyzed where the results have determined a significant estimation error. Afterwards, a table of calculated correlations has been offered for engineers in order to be used to prevent such unreliability.

Fig. 4 illustrates the monthly variation maps of $I_{\mathrm{s}}$ as a function of $V_{\mathrm{s}}$ and cell temperature, where the influence of NOCT in comparison to a NON-NOCT consideration based on seasonal horizon has been studied. Fig. 4(a),(b) and (c) present the autumn season, when the difference between NOCT and
NON-NOCT currents at higher voltages (14-22 V) can be seen on the September and October months. The sharp color map curvatures describe more voltage drop, mainly at the highest $V_{\mathrm{s}}$ when the NOCT is considered. In contrast, the variation of $I_{\mathrm{S}}$ appears more linear in the month of November, approximately similar to the NON-NOCT condition. Fig. 4(d), (e) and (f) indicate the winter, where insignificant errors of estimation are observed due to the lower $I_{\mathrm{s}}$. Among the three months of winter, Fig. 4(f) (Feb) shows sharper and wider curvatures which mean a higher risk of reliability in the output estimation. The curvature range is between $18-22 \mathrm{~V}$ in this season. In spring (Fig. 4(g), (h) and (i)), a larger estimation error exists in
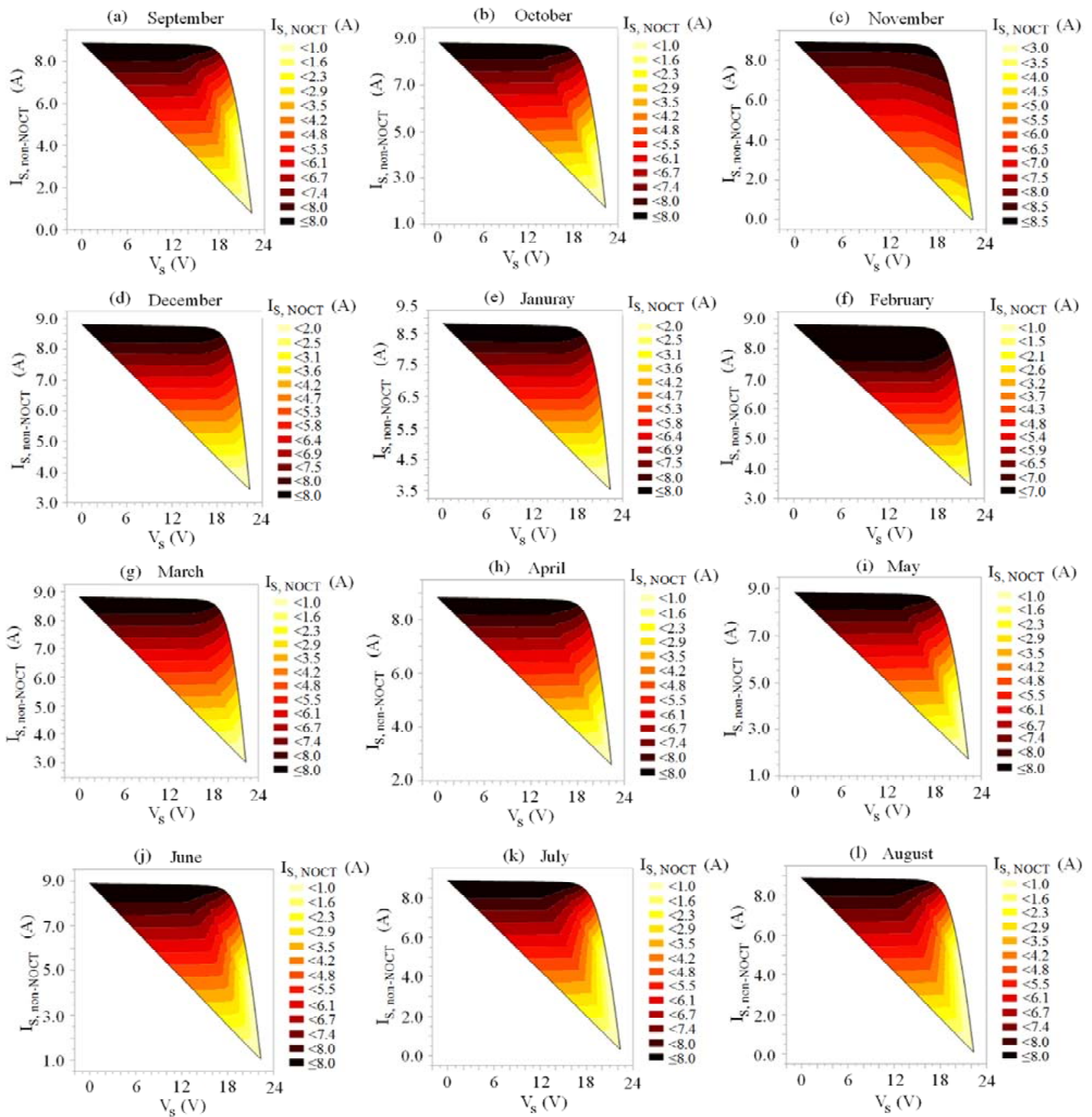

Fig. 4. Nominal output characteristic maps of the used solar C-Si module with and without nominal operating cell temperature (NOCT) consideration for (a) September, (b) October, (c) November, (d) December, (e) January, (f) February, (g) March, (h) April, (i) May, (j) June, (k) July, and (l) August. 

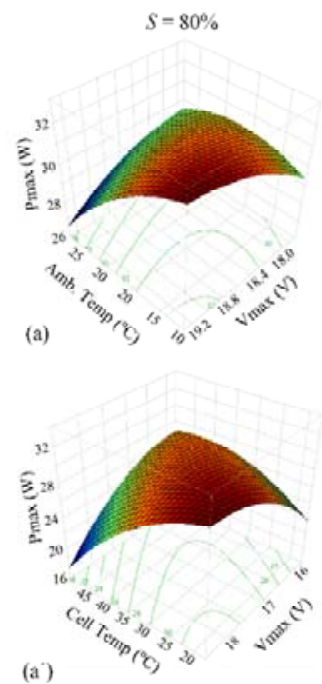
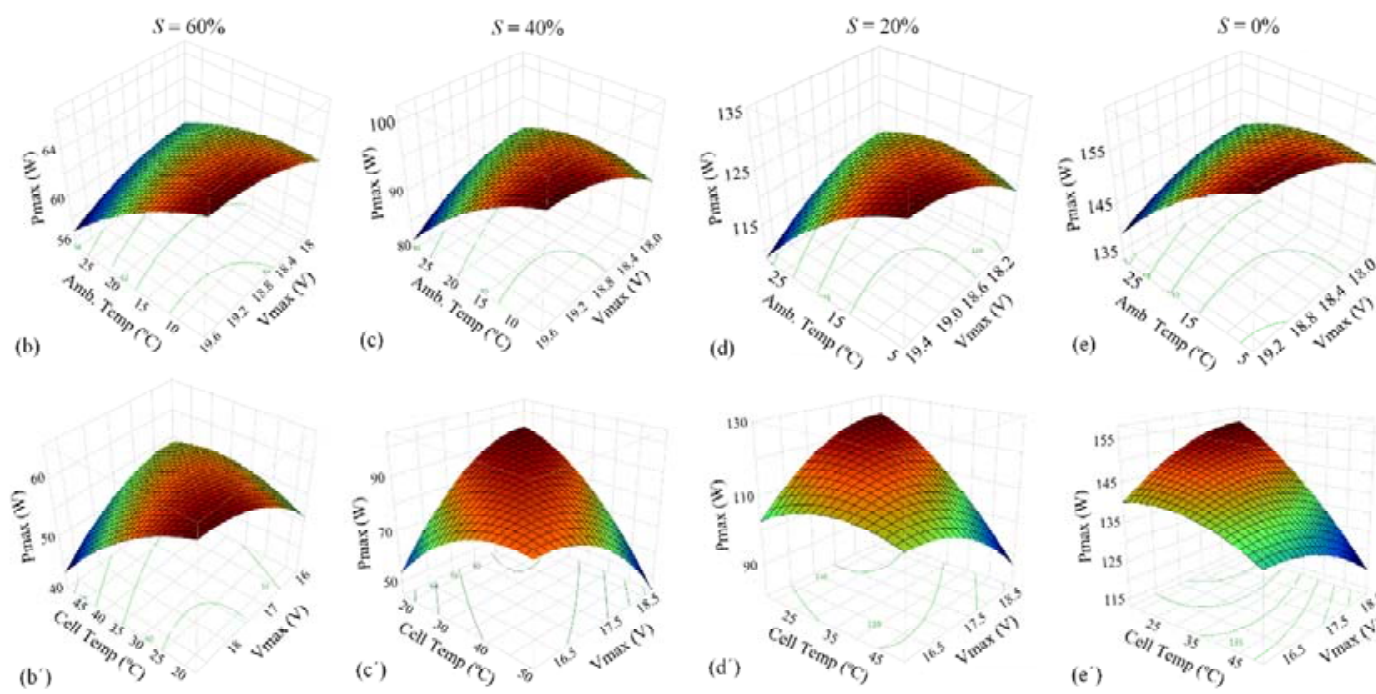
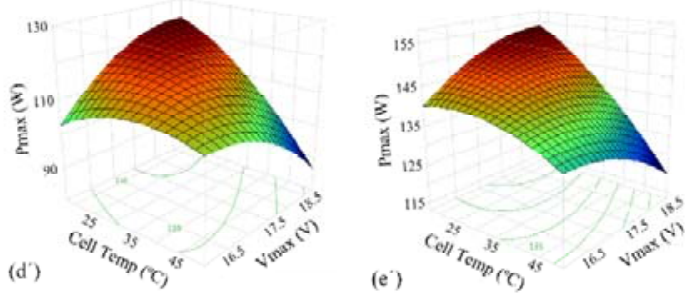

Fig. 5 Maximum output power based on partial shading range evaluation under conventional (non-NOCT) and NOCT computations, (a) $\mathrm{S}=80 \%$ and non-NOCT, (a') $\mathrm{S}=80 \%$ and NOCT, (b) $\mathrm{S}=60 \%$ and non-NOCT, (b') $\mathrm{S}=60 \%$ and NOCT, (c) $\mathrm{S}=40 \%$ and non-NOCT, (c') S=40\% and NOCT, (d) S=20\% and non-NOCT, (d') $\mathrm{S}=20 \%$ and NOCT, (e) $\mathrm{S}=0 \%$ and non-NOCT, and (e') $\mathrm{S}=0 \%$ and NOCT considerations.

comparison with autumn and winter, in which more nonlinear curves can be seen, especially in the range of 15-22 V. With respect to spring's maps, the most critical error occurs in the month of May within 14-22 V operation. During the summer, the current's maps have tended significantly towards the NOCT consideration, where the largest ramped curves occur at a different level of $I_{\mathrm{s}}(0.5-9 \mathrm{~A})$, and $V_{\mathrm{s}}(12-22 \mathrm{~V})$. The highlights of the presented current maps (Fig. 4) are; more estimation error exists when $V_{\mathrm{s}}$ is approaching the rated value $V_{\mathrm{m}}$ of the solar module, which mostly affects the peak operation months (Jun, Jul, and Aug). If the difference between the currents with and without the NOCT consideration defines the error of the $I_{\mathrm{s}}$ calculation, then the most critical error occurs during the widest range of $V_{\mathrm{s}}$ as well as a higher gradient. Therefore, the current prediction highly depends on the cell temperature and nominal voltage especially during peak operation times such as the summer season.

Fig. 5 presents the variation of maximum output power and voltage as function of ambient temperature for conventional and NOCT cases. For various rates of partial shading (0-80\%), the predicted values based on the conventional measurement have a significant estimation error. The study proofs that the maximum error of power prediction occurred at the higher rate of partial shading $S$. In other words, a larger rate of S and $V_{\mathrm{s}}$ led to power prediction inaccuracy (error). Hence, more nonlinearity in the prediction error has been presented. On cloudy days $(S=80 \%)$, the variation of maximum output power shown in Fig. 5(a) and $\left(a^{\prime}\right)$ have resulted in a negligible estimation error $\leq 3 \%$ because of a lower voltage drop of $V_{\mathrm{s}}$. Fig. 5 (b) illustrates the maximum extracted output power of $65 \mathrm{~W}$ during the partial shading condition without a NOCT consideration. Whereas, the maximum achieved power with the NOCT consideration is $62 \mathrm{~W}$. On average, an estimation error about $4.5 \%$ has been noted. Under a partial shading of $S=40 \%$, a maximum power of $98 \mathrm{~W}$ (non-NOCT), and $94 \mathrm{~W}$ (NOCT) could be seen with an error of $6.5 \%$, shown in Fig. 5(c) and Fig. 5(c'), respectively. In Fig. 5(d), the maximum power based on the non-NOCT case was recorded as $131 \mathrm{~W}$, while more heat loss for the NOCT consideration (Fig. 5(d')) shows a maximum power of $126 \mathrm{~W}$. In addition to a higher rate of $G$, larger heat loss has been observed, thus, the estimation error has slightly increased to $8.8 \%$. The highest rate of estimation error occurs when the maximum possible rate of $G=1000 \mathrm{~W} \cdot \mathrm{m}^{-2}, S=0 \%$ (no shading) strikes the C-Si module. Then, the cell temperature raises, and accordingly the heat loss in each cell, which only can be modeled if the NOCT is considered. Fig. 5(e) depicts the maximum available output power $(158 \mathrm{~W})$ through C-Si PV module used under the ideal conditions of highest rate of solar irradiance and no partial shading. Whereas, the true value of output power is recorded as $154 \mathrm{~W}$ under the NOCT consideration (shown in Fig. 5(e')). A significant error estimation of $9.7 \%$ (annual average) was noted.

Fig. 6 illustrates the estimation error trend for the whole year, if using the non-NOCT technique and not the proposed measurement method described in this research. The estimation error increases when less partial shading and a higher rate of solar irradiance $(G)$ hits the PV cells. The worst-case estimation error occurs in August, and generally during the summer season.

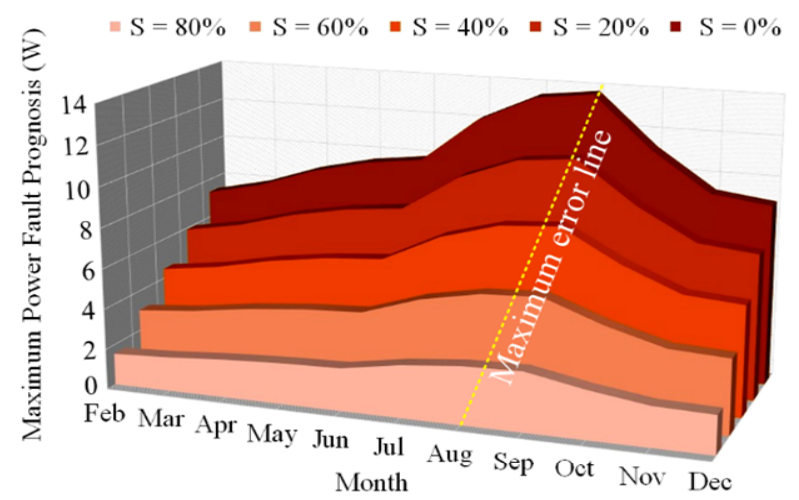

Fig. 6. Monthly spectrum of the estimation error.

Fig. 7 depicts the temperature distribution over the module tested in August, in which the impact of NOCT has been highlighted. Fig. 7(a) presents the module with an open-circuit 
load connected. In contrast, the module under the proposed measurement with a NOCT consideration is shown in Fig. 7(b), where an average temperature of $3.6{ }^{\circ} \mathrm{C}$ is the difference (error). Temperature predictions through an infrared thermometer and NTC sensors at an irradiance of $800 \mathrm{~W} \cdot \mathrm{m}^{-2}$ are set for the simulation. The peak temperature for both heat measurements are $53{ }^{\circ} \mathrm{C}$ and $52^{\circ} \mathrm{C}$ respectively. All the 45 NTC sensors have been calibrated to $60^{\circ} \mathrm{C}$ prior to the experiment.

To avoid such estimation error, this study has provided a set of non-parametric and parametric correlations with minimum error in order to simplify the process of measurement and importantly reduce the cost in both primary and post-processing predictions for engineers. Spearman's $\rho\left(r_{s}\right)$ and Kendall $\tau$ rank correlation coefficients methodologies have been computed. Unlike the Pearson's method, the Spearman's $\rho$ does not need an assumption of linearity in the relationship of the defined variables [30], which can be calculated using non-parametric model for a sample of $n$ size:

$$
r_{s}=\rho_{r g_{X}, r g_{Y}}=\frac{\operatorname{cov}\left(r g_{X}, r g_{Y}\right)}{\sigma_{r g_{X}} \cdot \sigma_{r g_{Y}}}
$$

where $\rho$ is the Pearson correlation coefficient, $\operatorname{cov}\left(\operatorname{rg}_{X}, \operatorname{rg}_{Y}\right)$ is the covariance of the rank variables, and $\sigma_{\mathrm{rgx}}$ and $\sigma_{\mathrm{rgY}}$ are the standard deviations of the rank variables.

The Kendall $\tau$ rank correlation also identifies monotonic relationships, which can be defined as:

$$
\tau(X, Y)=\frac{(\text { number of discordant pairs })}{0.5 n(n-1)}
$$

where concordant means the ranks for both elements agree, that is, if both $x_{\mathrm{i}}>x_{\mathrm{j}}$ and $y_{\mathrm{i}}>y_{\mathrm{j}}$ or if both $x_{\mathrm{i}}<x_{\mathrm{j}}$ and $y_{\mathrm{i}}<y_{\mathrm{j}}$. On the other hand, discordant means, if $x_{\mathrm{i}}>x_{\mathrm{j}}$ and $y_{\mathrm{i}}<y_{\mathrm{j}}$ or if $x_{\mathrm{i}}<x_{\mathrm{j}}$ and $y_{\mathrm{i}}>y_{\mathrm{j}}$. In an exceptional case, if $x_{\mathrm{i}}=x_{\mathrm{j}}$ or $y_{\mathrm{i}}=y_{\mathrm{j}}$, the pair is neither concordant nor discordant. Both correlation methods vary between fully opposed $(-1)$ to identical $(+1)$ for a correlation, and the interpretations are the same for the Spearman's correlation [30].

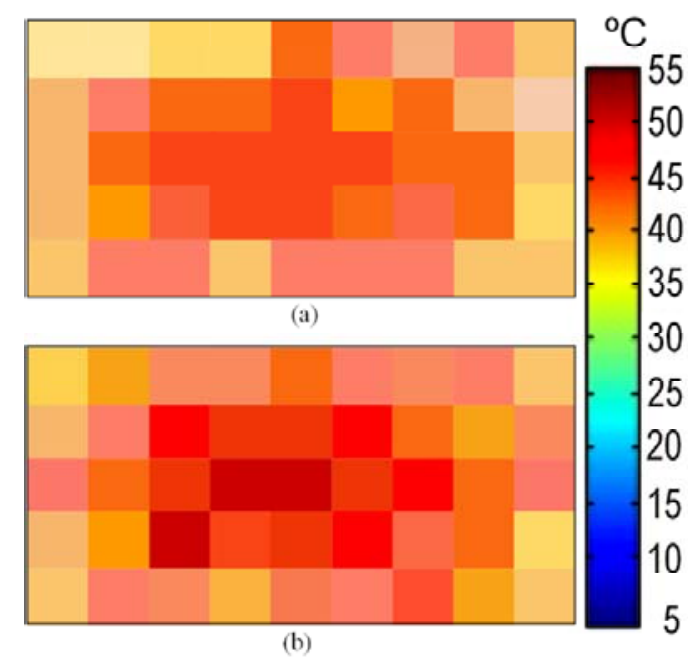

Fig. 7.5 by 9 interpolated heat distribution during peak time with solar irradiance of $1000 \mathrm{~W} \cdot \mathrm{m}^{-2}$, under $S=0 \%$, where (a) non-NOCT, and (b) NOCT.
Table I presents the non-parametric correlations using Spearman's $\rho$, and Kendall $\tau$ rank with very high significant probability of $<0.0001$. As illustrated, a correlation of 0.9859 can be injected to the output power estimated values in order to extract the true values, which are tested through the proposed technique (shown in Fig. 1(b)). As the variation is nearly linear during various partial shading rate, therefore, the correlations are independent of $S$.

TABLE I. OUtPut Power CORRELATION BASED ON $S$ RATE

\begin{tabular}{c|ccc}
\hline \hline Partial shading & Spearman's $\rho$ & Kendall's $\tau$ & Signif probability \\
\hline $\mathrm{S}=80 \%$ & 0.9859 & 0.9458 & $<0.0001^{*}$ \\
$\mathrm{~S}=60 \%$ & 0.9859 & 0.9458 & $<0.0001^{*}$ \\
$\mathrm{~S}=40 \%$ & 0.9859 & 0.9458 & $<0.0001^{*}$ \\
$\mathrm{~S}=20 \%$ & 0.9859 & 0.9458 & $<0.0001^{*}$ \\
$\mathrm{~S}=0 \%$ & 0.9859 & 0.9458 & $<0.0001^{*}$ \\
\hline \hline
\end{tabular}

\section{EXPERIMENTAL VERIFICATIONS}

Experimental measurements and tests are presented to verify the validity of the proposed technique of prediction in the coast of Barcelona city (Spain). The experimental results have been provided using actual total cell temperature estimation and maximum power point tracking (MPPT), where a DC-DC converter and variable DC load have been employed in a designed Hardware-in-the-loop configuration shown in Fig. 8.

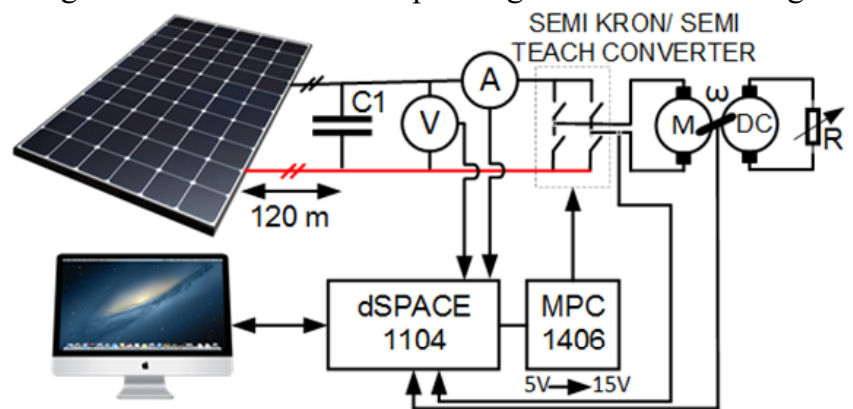

Fig. 8. The hardware-in-the-loop configuration designed for experimental validation.

The implemented experimental setup is represented in Fig. 9. The Solar PV module with parameters as listed in Table II, has been installed out of the laboratory through approximately $120 \mathrm{~m}$ of cables. A $100 \mu \mathrm{F}$ filter capacitor which is further connected to the SEMITEACH B6U+E1CIF+B6CI converter with IGBT switches are used as the interface between the PV module and the DC load. A brushless DC motor (MotorSolver DCMOT8077), with parameters as listed in Table III, coupled with a DC generator with the same parameters are utilized as the DC load. By changing the variable resistor connected at the DC generator's terminal, the mechanical load on the DC motor's shaft changes and different loading scenarios can be achieved during the cell temperature measurements. The MPPT system with an average switching frequency of $5 \mathrm{kHz}$ is implemented in a MATLAB/Simulink environment and the obtained pulses have been sent to the converter through dSPACE1104. Load voltage and current are measured with LEM LV25-P and LEM LA25- NP voltage and current transducers, respectively and they have been sent to the MPPT algorithm. A Microchip MCP1406 IC is also utilized at the dSPACE 1104 output to regulate the pulse amplitude. 


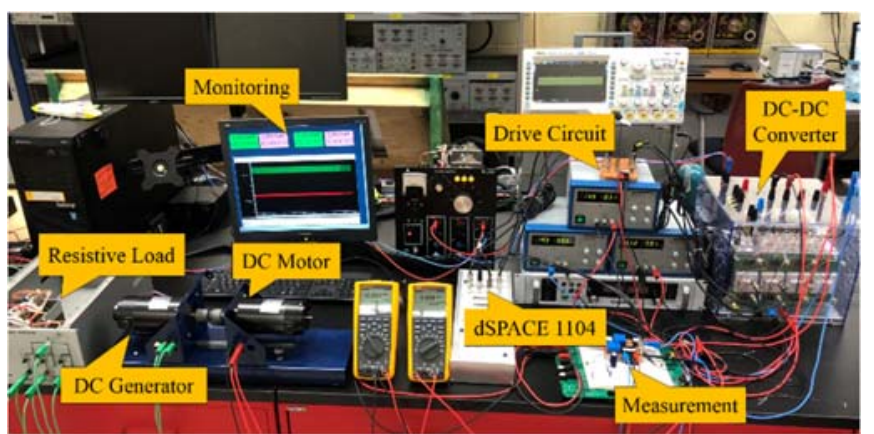

Fig. 9. Experimental setup for proposed technique validation.

TABLE II

PV MODULE PARAMETERS

\begin{tabular}{ll}
\hline \hline \multicolumn{1}{c}{ Parameter } & \multicolumn{1}{c}{ Value } \\
\hline open circuit voltage $\left(V_{\text {oc }}\right)$ & $21.06 \mathrm{~V}$ \\
short circuit current $\left(I_{\mathrm{SC}}\right)$ & $8.62 \mathrm{~A}$ \\
MPP voltage $\left(V_{\mathrm{MPP}}\right)$ & $17.09 \mathrm{~V}$ \\
MPP current $\left(I_{\mathrm{MPP}}\right)$ & $7.62 \mathrm{~A}$ \\
number of cells & $36(4 \times 9)$ \\
\hline \hline
\end{tabular}

TABLE III

\begin{tabular}{ll}
\multicolumn{2}{c}{ DC LOAD PARAMETERS } \\
\hline \hline \multicolumn{1}{c}{ Parameter } & \multicolumn{1}{c}{ Value } \\
\hline Rated Power & $250 \mathrm{~W}$ \\
Maximum Voltage & $42 \mathrm{~V}$ \\
Maximum Speed & $4000 \mathrm{rpm}$ \\
No-load Current & $0.97 \mathrm{~A}$ \\
Voltage Constant $\left(\mathrm{K}_{\mathrm{e}}\right)$ & $0.0087 \mathrm{~V} / \mathrm{rpm}$ \\
Armature Resistance $\left(\mathrm{R}_{\mathrm{a}}\right)$ & $3.9 \Omega$ \\
Armature Inductance $\left(\mathrm{L}_{\mathrm{a}}\right)$ & $0.665 \mathrm{mH}$ \\
\hline \hline
\end{tabular}

Table IV shows the monthly maximum output power which was acquired by the utilized MPPT. The values have been experimentally supplied via a resistive load through the $250 \mathrm{~W}$ DC motor-generator setup described earlier. Fig. 11 illustrates the total cell temperature estimation under non-NOCT (conventional) and NOCT setup considerations (drawn in Fig. 1(a)-(b)).

On August 20 2017 (peak time, sunny day), the cell temperature measurement was recorded through the 45 NTC sensors technique reported in [31] (as graphed in Fig. 10). The impact of this graph relies on error predicting of both the measurement techniques, $T_{2}>T_{1}$, where $T_{2}$ deals with the true temperature under a condition of full load. The $T_{1}$ trend (conventional) accounts only for the temperature of the

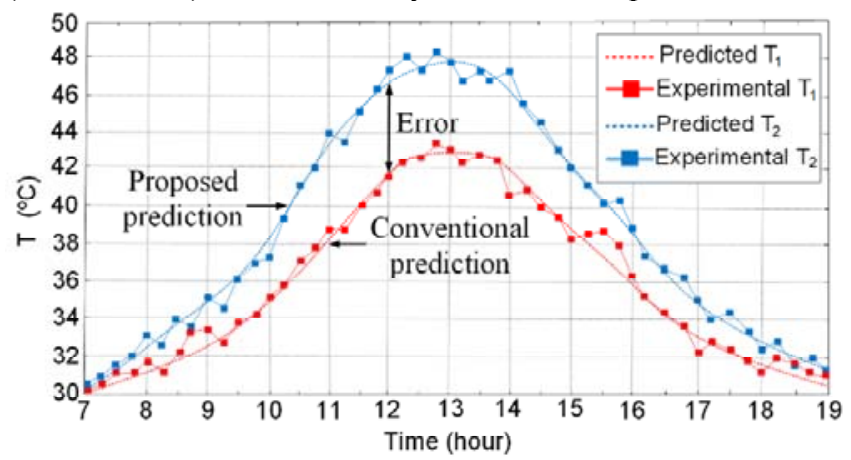

Fig. 10. Experimental cell temperature using non-NOCT and NOCT considerations during the peak operation time ( $20^{\text {th }}$ of August, 2017). module's surface due to the no-load measurement. The accuracy of each measurement test is approximately less than $0.1 \%$.

TABLE IV. MEASURED MAXIMUM OUTPUT POWER UNDER DIFFERENT RATE OF $S$, AND $G=1000 \mathrm{~W} \cdot \mathrm{M}^{-2}$

\begin{tabular}{l|cccccc}
\hline \hline Month & Unit & $\boldsymbol{S}=\mathbf{8 0} \%$ & $\boldsymbol{S = 6 0 \%}$ & $\boldsymbol{S = 4 0 \%}$ & $\boldsymbol{S}=\mathbf{2 0} \%$ & $\boldsymbol{S}=\mathbf{0 \%}$ \\
\cline { 2 - 7 } Jan & W & 30.372 & 61.584 & 92.355 & 122.420 & 151.653 \\
Feb & W & 30.176 & 61.202 & 91.791 & 121.675 & 150.729 \\
Mar & W & 29.717 & 60.309 & 90.471 & 119.932 & 148.566 \\
Apr & W & 29.322 & 59.540 & 89.335 & 118.432 & 146.705 \\
May & W & 28.727 & 58.382 & 87.624 & 116.173 & 143.902 \\
Jun & W & 27.863 & 56.698 & 85.136 & 112.890 & 139.829 \\
Jul & W & 27.193 & 55.395 & 83.210 & 110.349 & 136.677 \\
Aug & W & 26.992 & 55.002 & 82.631 & 109.584 & 135.728 \\
Sep & W & 27.930 & 56.828 & 85.328 & 113.143 & 140.143 \\
Oct & W & 28.860 & 58.640 & 88.005 & 116.676 & 144.526 \\
Nov & W & 29.520 & 59.925 & 89.904 & 119.183 & 147.636 \\
Dec & W & 30.372 & 61.584 & 92.355 & 122.420 & 151.653 \\
\hline \hline
\end{tabular}

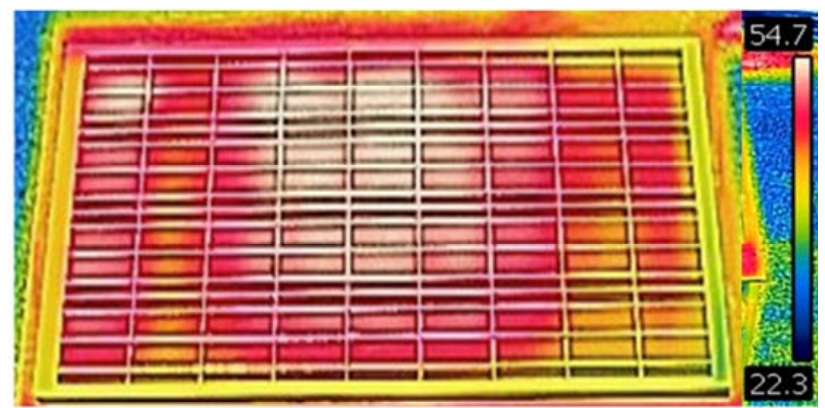

(a)

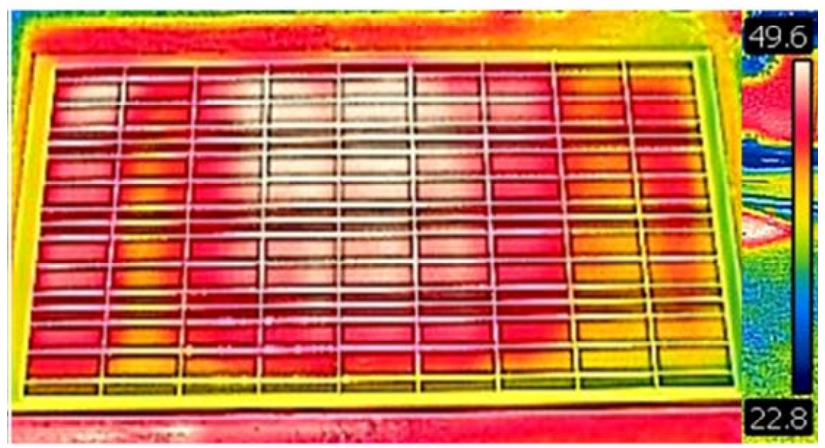

(b)

Fig. 11. IR thermo-graphs of C-Si PV module under grid-connected condition in the open rack. a) IR thermo-graphs of module under grid-connected (NOCT), and b) and the open-circuit (non-NOCT).

\section{CONCLUSION}

In this research, a new technique of measurement has been studied without any assumptions, in which a NOCT consideration was accounted for under different ranges of partial shading effects during the whole year. To minimize the error of the output power prediction, both techniques of measurements, conventional and proposed were examined through equal conditions to present the difference (error) between them. Afterwards, the impact of the proposed technique has been modified into the output results of the 
conventional technique via non-parametric correlations, known as the Spearman's $\rho$, and Kendall $\tau$ rank methods. This paper offers these correlations under different rates of partial shading to reduce the cost and complexity in design. The contribution of this investigation can be used by engineers in prediction studies with less than $0.1 \%$ error, regardless of the assumptions and considerations of which they applied for their measurements. The measurements data including current, voltage, and output power have been experimentally verified where the proposed measurement technique brought the true estimation because of full environmental considerations such as cell temperature, and partial shading.

\section{REFERENCES}

[1] O. Dupre, R. Vaillon, and M. A. Green "Experimental Assessment of Temperature Coefficient Theories for Silicon Solar Cells," IEEE $J$. Photovolt., V.6, N.1, pp.56-60, 2016.

[2] W-C. Yang, C. Lo, C-Y. Wei, and W-S. Lour "Cell-Temperature Determination in InGaP-(In)GaAs-Ge Triple-Junction Solar Cells," IEEE Electron Device Letters, V.32, N.10, pp.1412-1414, 2011.

[3] D. A-Alvarez, E. Klamaftis, D. Ross, and B. S. Richards "External Thermalization of Carriers With Luminescent Down Shifting for Lower Operating Solar Cell Temperature," IEEE J. Photovolt., V.4, N.6, pp.1532-1537, 2014.

[4] S. Hara, M. Kasu, and N. Matsui "Estimation Method of Solar Cell Temperature Using Meteorological Data in Mega Solar Power Plant," IEEE J. Photovolt., V.6, N.5, pp.1255-1260, 2016.

[5] J. J. Wysocki and P. Rappaport, "Effect of temperature on photovoltaic solar energy conversion," J. Appl. Phys., vol. 31, no. 3, pp. 571-578, 1960.

[6] M. A. Green, Solar Cells: Operating Principles, Technology, and System Applications. Englewood Cliffs, NJ, USA: Prentice-Hall, 1982.

[7] D. S. H. Chan and J. C. H. Phang, "Analytical methods for the extraction of solar-cell single- and double-diode model parameters from I-V characteristics," IEEE Trans. Electron Devices, vol. ED-34, no. 2, pp. 286-293, Feb. 1987.

[8] M. Itoh, H. Takahashi, T. Fujii, H. Takakura, Y. Hamakawa, and Y. Matsumoto "Evaluation of electric energy performance by democratic module PV system field test," Solar Energy Mater. Solar Cells, vol. 67, nos. 1-4, pp. 435-440, 2001.

[9] M. D’Orazio, C. Di Perna, and E. Di Giuseppe, “Experimental operating cell temperature assessment of BIPV with different installation configurations on roofs under Mediterranean climate," Renewable Energy, vol. 68, pp. 378-396, 2014.

[10] D. Polverini, M. Field, E. Dunlop, and W. Zaaiman, "Polycrystalline silicon PV modules performance and degradation over 20 years," Prog. Photovoltaics, Res. Appl., vol. 21, no. 5, pp. 1004-1015, 2013.

[11] G. Makrides, B. Zinsser, M. Schubert, and G. E. Georghiou, "Performance loss rate of twelve photovoltaic technologies under field conditions using statistical techniques," Sol. Energy, vol. 103, pp. 28-42, 2014.

[12] M. A. Green, "General temperature dependence of solar cell performance and implications for device modelling," Prog. Photovoltaics, Res. Appl., vol. 11, no. 5, pp. 333-340, 2003.

[13] K. J. Sauer, T. Roessler, and C. W. Hansen, "Modeling the irradiance and temperature dependence of photovoltaic modules in pvsys," IEEE J. Photovolt., vol. 5, no. 1, pp. 152-158, Jan. 2015.

[14] V. D. Rumyntsev et al., "Evaluation of the pv cell operation temperature in the process of fast switching to open-circuit mode," IEEE J. Photovolt., vol. 5, no. 6, pp. 1715-1721, Nov. 2015.

[15] S. De Wolf, A. Descoeudres, Z. C. Holman, and C. Ballif, "Highefficiency silicon heterojunction solar cells: A review," Green, vol. 2, pp. 7-24, 2012.

[16] K. Masuko et al., "Achievement of more than $25 \%$ conversion efficiency with crystalline silicon heterojunction solar cell," IEEE J. Photovoltaics, vol. 4, no. 6, pp. 1433-1435, Nov. 2014.

[17] C. Ballif, S. De Wolf, A. Descoeudres, and Z. C. Holman, "Amorphous silicon/crystalline silicon heterojunction solar cells," Semicond. Semimetals, vol. 90, pp. 73-120, 2014.
[18] T. Sen, N. Pragallapati, V. Agarwal, and R. Kumar "Global maximum power point tracking of $\mathrm{PV}$ arrays under partial shading conditions using a modified particle velocity-based PSO technique," IET Renewable Power Gen., V.12, N.5, pp.555-563, 2018.

[19] E. I. Batzelis, P. S. Georgilakis, and S. A. Papathanassiou, "Energy models for photovoltaic systems under partial shading conditions: a comprehensive review," IET Renewable Power Gen., V.9, N.4, pp.340$349,2015$.

[20] G. Farivar, and B. Asaei "A New Approach for Solar Module Temperature Estimation Using the Simple Diode Model," IEEE Trans. Energy Conv., V.26, N.4, pp.1118-1126, 2011.

[21] G. Mangeni, R. H. G. Tan, T. H. Tan, S. K. Cheo, V. H. Mok, and J. Y. Pang "Photovoltaic Module Cell Temperature Measurements using Linear Interpolation Technique," IEEE Int. Conf. Inst. and Measurement (I2MTC), DOI: 10.1109/I2MTC.2017.7969759, pp.1-6, 2017.

[22] M. R. Vogt, H. S-Huxel, M. Offer, S. Blankemeyer, R. Witteck, M. Kontges, K. Bothe, and R. Brendel "Reduced Module Operating Temperature and Increased Yield of Modules With PERC Instead of AlBSF Solar Cells," IEEE J. Photovolt.., V.7, N.1, pp.44-50, 2017.

[23] P. Ingenhoven, G. Belluardo, and D. Moser "Comparison of Statistical and Deterministic Smoothing Methods to Reduce the Uncertainty of Performance Loss Rate Estimates," IEEE J. Photovolt., V.8, N.1, pp.224$232,2018$.

[24] V. Sharma and S. S. Chandel, "Performance and degradation analysis for long term reliability of solar photovoltaic systems: A review," Renewable Sustain. Energy Rev., vol. 27, pp. 753-767, 2013.

[25] A. Ndiaye et al., "Degradations of silicon photovoltaic modules: A literature review," Sol. Energy, vol. 96, pp. 140-151, 2013.

[26] S. Zhang, H. Wang, X. Zou, Y. Zhang, R. Lu, H. Li, and Y. Liu, "Optical Frequency-Detuned Heterodyne for Self-Referenced Measurement of Photodetectors," IEEE Photonics Tech. Letter., V.27, N.9, pp.1014-1017, 2015.

[27] C. Iaconis, and I. A. Walmsley, "Self-Referencing Spectral Interferometry for Measuring Ultrashort Optical Pulses," IEEE Journal of Quantum, V.35, N.4, pp.501-509, 1999.

[28] J. Yin, T. Liu, J. Jiang, K. Liu, S. Wang, S. Zou, Z. Qin, and Z. Ding "SelfReferenced Residual Pressure Measurement Method for Fiber-Optic Pressure Sensor Chip," IEEE Photonics Tech. Letter., V.26, N.10, pp.272277, 2014.

[29] M. Mohsenizadeh, F. Gasbarri, M. Munther, A. Beheshti, and K. Davami, "Additively-manufactured lightweight Metamaterials for energy absorption," Materials and Design (Elsevier), vol. 139, no. 11, pp. 521$530,2018$.

[30] S. S. Santos, D. Y. Takahashi, A. Nakata, and A. Fujita, "A comparative study of statistical methods used to identify dependencies between gene expression signals," Briefings in Bioinformatics, DOI:10.1093/bib/bbt051, pp. 1-13, 2013.

[31] Z. Zhen, X. Taoyun, S. Yanping, L. Wang, P. Jia and J. Yu "A Method to Test Operating Cell Temperature for BIPV Modules," IEEE J. Photovolt., V.6, N.1, pp.272-277, 2016. 